\title{
TAE226, a dual inhibitor for FAK and IGF-IR, has inhibitory effects on mTOR signaling in esophageal cancer cells
}

\author{
ZHI GANG WANG ${ }^{1,2}$, TAKUYA FUKAZAWA ${ }^{2}$, TOSHIO NISHIKAWA ${ }^{2}$, NOBUYUKI WATANABE ${ }^{2}$, \\ KAZUFUMI SAKURAMA ${ }^{2}$, TAKAYUKI MOTOKI ${ }^{2}$, MUNENORI TAKAOKA ${ }^{2}$, \\ SHINJI HATAKEYAMA ${ }^{3}$, OSAMU OMORI ${ }^{3}$, TOSHIAKI OHARA ${ }^{2}$, \\ SHUNSUKE TANABE ${ }^{2}$, YASUHIRO FUJIWARA ${ }^{2}$, YASUHIRO SHIRAKAWA ${ }^{2}$, \\ TOMOKI YAMATSUJI ${ }^{2}$, NORIAKI TANAKA ${ }^{2}$ and YOSHIO NAOMOTO ${ }^{2}$
}

\begin{abstract}
${ }^{1}$ College of Life Science, Inner Mongolia University, The Key Laboratory of Mammal Reproductive Biology and Biotechnology, Ministry of Education, Huhhot 010021, P.R. China; ${ }^{2}$ Department of Gastroenterological Surgery, Transplant, and Surgical Oncology, Graduate School of Medicine, Dentistry and Pharmaceutical Sciences, Okayama University, 2-5-1 Shikata-cho, Okayama 700-8558, Japan; ${ }^{3}$ Novartis Institutes for BioMedical Research, Basel, Switzerland
\end{abstract}

Received July 3, 2008; Accepted September 4, 2008

DOI: 10.3892/or_00000168

\begin{abstract}
Esophageal cancer is one of the most aggressive cancers in the world. Novel preventive and therapeutic strategies tend to target the key molecules involved in the signaling transduction pathways for cell growth. It is known that FAK and mTOR are important controllers of cell growth. TAE226, a novel small molecule compound, is a potent ATP competitive inhibitor of FAK and IGF-IR. TAE226 can block FAK and IGF-IR signaling pathways. The purpose of this study was to explore the inhibitory effects on mTOR signaling and the mechanism of cell growth suppression by TAE226. We examined the expression of mTOR and S6 in esophageal cancer cells (SEG-1) and normal esophageal epithelial cells (KOB-13) and the efficacy of TAE226 against SEG-1 cells. mTOR and S6 were overexpressed in SEG-1 cells compared with KOB-13 cells. TAE226 inhibited the expression of mTOR, Akt, p70S6K and S6 as well as the phosphorylation of mTOR (Ser2448), Akt (Ser473), p70S6K (Thr389) and S6 (Ser240/244). As a result, TAE226 induced a dose-dependent decrease in cell growth (number) and damage in the cell shape. Together, these data show that TAE226 has potent inhibitory effects on mTOR signaling and esophageal cancer cell growth indicating that TAE226 has potential application in esophageal cancer treatment.
\end{abstract}

Correspondence to: Dr Yoshio Naomoto, Department of Gastroenterological Surgery, Transplant, and Surgical Oncology, Graduate School of Medicine, Dentistry and Pharmaceutical Sciences, Okayama University, 2-5-1 Shikata-cho, Okayama 7008558, Japan

E-mail: ynaomoto@md.okayama-u.ac.jp

Key words: TAE226, mTOR signaling, cell growth, esophageal cancer

\section{Introduction}

Esophageal cancer is one of the most aggressive cancers in the world. The incidence rate of esophageal carcinoma differs greatly among different regions and countries depending on race, eating habits and environment. It is estimated there are 462,000 newly occurring cases and 38,600 deaths per year, the death to incidence ratio reaching 0.8 (1-4).

Focal adhesion kinase (FAK), MW $125 \mathrm{kDa}$, is a member of a family of non-receptor protein-tyrosine kinases expressed in normal and cancer cells. FAK can regulate cell proliferation, motility, invasion, apoptosis, death and angiogenesis (5-8). Growth factors and integrins can arouse the autophosphorylation of FAK on tyrosine 397 (Tyr397) and then lead to the phosphorylation of several other tyrosine residues, including Tyr407, 576, 577 and 925. Finally, Tyr861 becomes highly phosphorylated (9-11). Differences in the site of FAK tyrosine phosphorylation may contribute to the formation of signaling complexes which promote different biological effects. FAK is overexpressed in many tumors and can promote tumor growth.

IGF-IR belongs to the insulin receptor family and is mainly involved in the regulation of cell proliferation, antiapoptosis, differentiation and cell motility. IGF-IR is an intromembraneous receptor protein-tyrosine kinase, which can be activated by IGF-I and IGF-II. IGF-IR is expressed in almost all cells and overexpressed in tumors (12-14). IGF-IR is crucial for the proliferation and invasion of malignant cells but is only partially involved in normal cell growth.

TAE226, a novel small molecule compound, is a potent ATP competitive inhibitor of FAK and IGF-IR. TAE226 can block FAK and IGF-IR signaling pathways, which can result in the inhibition of growth and invasion of malignant cells, the disruption of cell cycle progression and the induction of apoptosis. It is known that TAE226 can effectively inhibit the proliferation of glioma $(15,16)$. We recently reported that TAE226 can inhibit the growth of esophageal cancer cells in vitro and in vivo (17). 


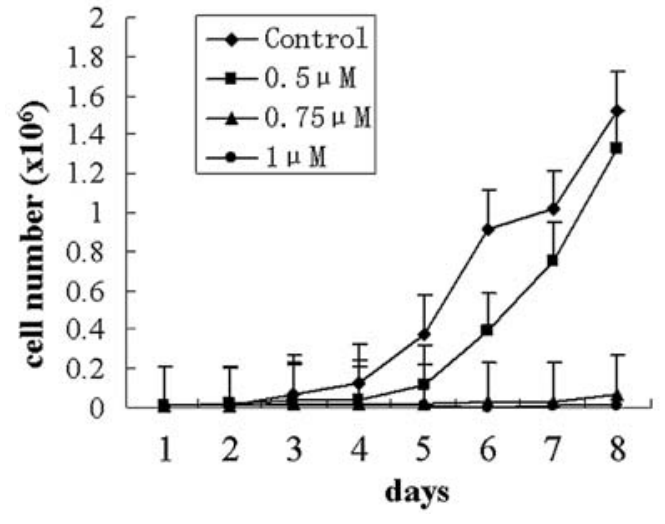

Figure 1. TAE226 suppresses growth of SEG-1 cells. TAE226 treatment started at day 1 and cell number in each condition was counted every $24 \mathrm{~h}$ until day 8. Each plot represents average cell number of triplicate and error bars represent standard deviation. Each plot mark represents the following: (u), control (DMSO only); (n), $0.5 \mu \mathrm{mol} / 1$ of TAE226; (s), $0.75 \mu \mathrm{mol} / 1$ of TAE226; (1), $1 \mu \mathrm{mol} / 1$ of TAE226.

It is well recognized that the PI3K/Akt signaling pathway is connected with the FAK and IGF-IR signaling pathways (18-21). TAE226 prevents the phosphorylation of FAK and IGF-IR, leading to changes in the activity of Akt and S6 and the inhibition of cellular proliferations $(15,16)$. In the PI3K/ $\mathrm{Akt} / \mathrm{mTOR}$ pathway, Akt is the upstream regulating kinase of mTOR, while S6 is the downstream target of mTOR, so TAE226 may inhibit the activity of mTOR.

In this study, we treated the esophageal cancer cell line SEG-1 with TAE226 to observe changes in the activity of mTOR and S6, to show the regulation of the FAK/PI3K/ mTOR signaling pathway on S6 and at least show that the signaling pathway has a partial role in cell growth regulation. Our data showed the inhibitory effects of TAE226 on mTOR signaling and esophageal cancer cell growth.

\section{Materials and methods}

Cell lines and culture conditions. To assess the levels of mTOR and S6 in human esophageal cancer as well as the effects of TAE226 on mTOR signaling, we used the cell lines SEG-1 (esophageal cancer cell line, a generous gift from Dr David Beer, University of Michigan) and KOB-13 (primary normal esophageal epithelial cells). SEG-1 cells were maintained as monolayer cultures in DMEM with L-glutamine (Sigma) supplemented with 10\% fetal bovine serum (FBS) and $100 \mathrm{U} / \mathrm{ml}$ penicillin G, $100 \mathrm{mg} / \mathrm{ml}$ streptomycin (FBS, Hyclone and penicillin/streptomycin, Sigma). KOB-13 cells were maintained as monolayer cultures in KSFM (L-glutamine ${ }^{+}$, Invitrogen) supplemented with EGF and BPE (Invitrogen). Cell cultures were maintained and incubated at $37^{\circ} \mathrm{C}$ in humidified air with $5 \% \mathrm{CO}_{2}$. Cellular morphology was observed through a light microscope during culture and experiments.

Reagents. TAE226, a dual tyrosine kinase inhibitor of FAK and IGF-IR, was synthesized and generously provided by Novartis Pharma AG (Basel, Switzerland) through a materials transfer agreement with Okayama University. TAE226 was dissolved in DMSO (Sigma Chemical Corp., St. Louis, MO) to a stock concentration of $20 \mathrm{mmol} / \mathrm{l}$, stored at $-20^{\circ} \mathrm{C}$, and further diluted to an appropriate final concentration with culture media before use. DMSO in the final solution did not exceed $0.1 \%(\mathrm{v} / \mathrm{v})$.

Measurement of cell proliferation. The antiproliferative activity of TAE226 on SEG-1 cells growing in culture was determined using a trypan blue exclusion assay. SEG-1 cells (1x104/well) were seeded directly in 24-well culture plates with medium for $24 \mathrm{~h}$ before drug treatment. Subconfluent cells were treated with different concentrations of TAE226 $(0.5,0.75$ and $1 \mu \mathrm{M})$ for $48 \mathrm{~h}$. Cells were harvested on the indicated day after treatment with trypsin, stained with trypan blue and counted using a hemacytometer. Growth curves were drawn using Microsoft excel software.

Cell shape assay. SEG-1 cells $\left(3 \times 10^{5} /\right.$ well) were seeded directly in 6-well culture plates with medium for $24 \mathrm{~h}$ before drug treatment. Cells were then treated with different concentrations of TAE226 $(0.1,1,3,6$ and $12 \mu \mathrm{M})$ for 24 and 48 h. Cells were imaged with a digital camera mounted to a light microscope (Olympus DP-70).

$R T-P C R$. Total RNA was prepared by RNAzol (Tel-Test Inc., USA) from SEG-1 and KOB-13 cells. RNA was reverse transcribed with a PrimeScript 1 st strand cDNA Synthesis kit according to the instructions of the manufacturer (Takara Biotechnology Co. Ltd., Japan). An input of $1 \mu \mathrm{g}$ total RNA was used for each reaction. Subsequent PCRs to detect mTOR and 3 -actin were carried out for 25, 30 and 35 cycles at the appropriate annealing temperature for the following pairs of primers: mTOR, forward: 5'-GAC CGT CTG AGT GGG AAG-3', reverse: 5'-TTA CCA GAA AGG GCA CCA G-3', the predicted fragment was 612 bp; $ß$-actin, forward: 5'-TTCCAGCCTTCCTTCCTG -3', reverse: 5'-CGG ACTC GTCATACTCCTGCT-3', the predicted fragment was $313 \mathrm{bp}$. Reactions were run in triplicate in two independent experiments. The PCR products were then electrophoresed and photos were taken by an electronic UV transilluminator (Ultralum, Inc.). mTOR gene PCR products were sequenced by Applied Biosystems.

Antibody. The following primary antibodies were used in this study: anti-mTOR, purchased from Epitomic Inc., antiphosphorylated mTOR (Ser2448), anti-phosphorylated p70S6K (Thr389), anti-S6, anti-phosphorylated S6 (Ser240/ 244), anti-Akt and anti-phosphorylated Akt (Ser473), purchased from Cell Signaling Technology, Inc., anti-p70S6K, purchased from Santa Cruz, and anti- $\beta$-actin, purchased from Sigma-Aldrich.

Western blot analysis. SEG-1 cells were plated onto 6-well plates at a concentration of $3 \times 10^{5}$ per well and then incubated for $24 \mathrm{~h}$ with medium. On the following day, cells were treated with different concentrations of TAE226 $(0.1,1,3$ and $6 \mu \mathrm{M})$ for $48 \mathrm{~h}$. Cell cultures were collected after treatment with trypsin and washed with cold PBS three times. Cells then were dissolved in a cell lysis buffer containing $20 \mathrm{mM}$ Tris (pH 8.0), $137 \mathrm{mM} \mathrm{NaCl}, 10 \%$ Glycerol, 5\% Triton X-100, $0.2 \% \mathrm{Na}_{2} \mathrm{VO}_{4}$ and $0.4 \%$ EDTA. Ten microliters PMSF (0.1 M) 


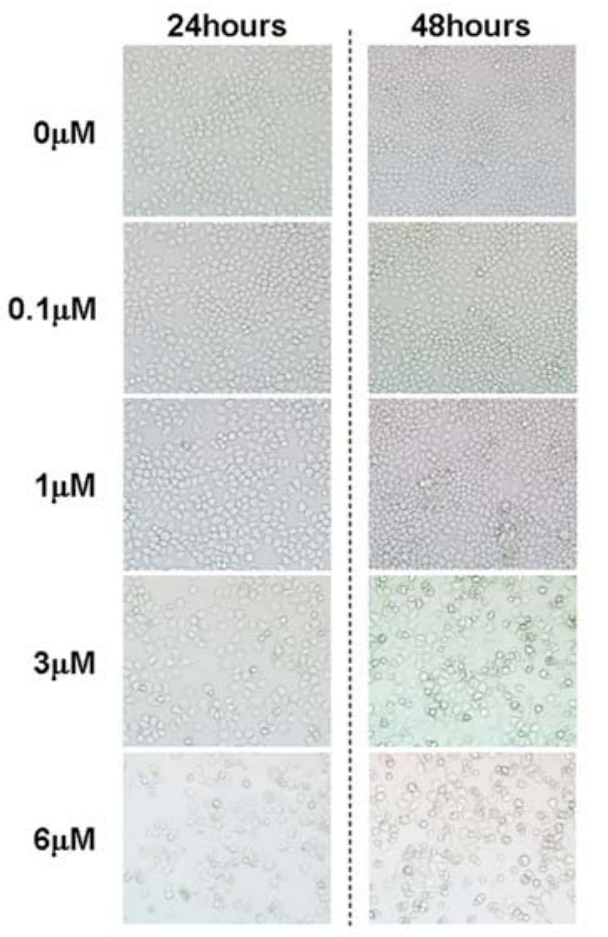

Figure 2. TAE226 induces severe morphological damage of SEG-1 cells. SEG-1 cells were treated with indicated concentrations of TAE226 and microscopic images were taken at $24 \mathrm{~h} \mathrm{(A)}$ and $48 \mathrm{~h}$ (B). Morphological change was observed in $24 \mathrm{~h}$ and cell density was obviously decreased by the treatment with the FAK inhibitor in a dose-dependent fashion.

and $10 \mu \mathrm{l}$ ALT $(10 \mathrm{mg} / \mathrm{ml})$ were added to each $1 \mathrm{ml}$ lysis buffer just before use. The buffer solution was iced for $15 \mathrm{~min}$ and centrifuged at $15,000 \mathrm{rpm}$ at $4^{\circ} \mathrm{C}$ for $20 \mathrm{~min}$. The concentration of protein lysates was measured by the BioRad protein determination method (Bio-Rad Laboratories, Hercules, CA). Equal amounts $(40 \mu \mathrm{g})$ of protein were electrophoresed under the conditions in 12 or $8 \%(\mathrm{w} / \mathrm{v})$ polyacrylamide gels. Proteins were then transferred to Hybond-polyvinylidene difluoride transfer membranes (Amersham, Arlington Heights, IL) and incubated with the primary antibodies at $4^{\circ} \mathrm{C}$ overnight, followed by incubation with peroxidase-linked secondary anti-bodies at room temperature for $1 \mathrm{~h}$. Amersham chemiluminescence Western system (Amersham) was used for signal detection.

Statistical analysis. Descriptive statistics were generated for all quantitative data, with presentation of the mean \pm SD.

\section{Results and Discussion}

TAE226 inhibited cell proliferation and damaged cell morphology in SEG-1 cells. FAK plays a critical role for integrin-mediated cell adhesion in the cultured adherent cells to maintain their growth and proliferation. In order to determine an inhibitory effect of TAE226 on cell growth, the anti-proliferative effect was examined by drawing growth curve. After seeding SEG-1 cells in plastic culture plates, the cells were treated with different concentrations of TAE226 $(0,0.5,0.75$ and $1 \mu \mathrm{M})$ from the next day (day 1$)$. The medium with the drug was refreshed every $48 \mathrm{~h}$ to continue the cell culture. The number of cells was counted everyday
A

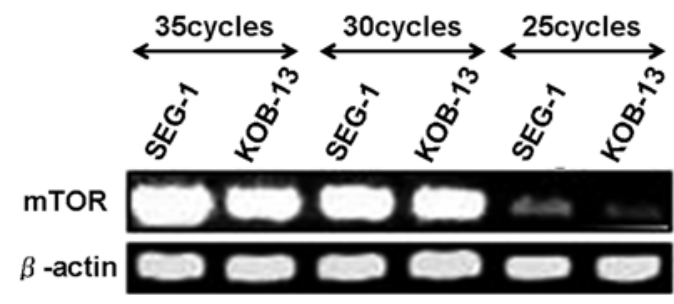

B

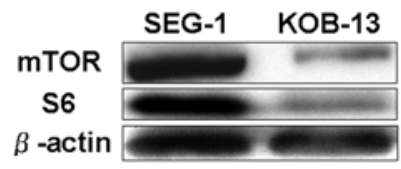

Figure 3. Expression of mTOR and S6 were higher in SEG-1 cells than in KOB-13 cells. (A) Expression of mTOR was detected by RT-PCR. (B) Expression of mTOR and S6 were detected by Western blot analysis. mTOR and S6 were overexpressed in SEG-1 cells compared with those in KOB-13 cells.

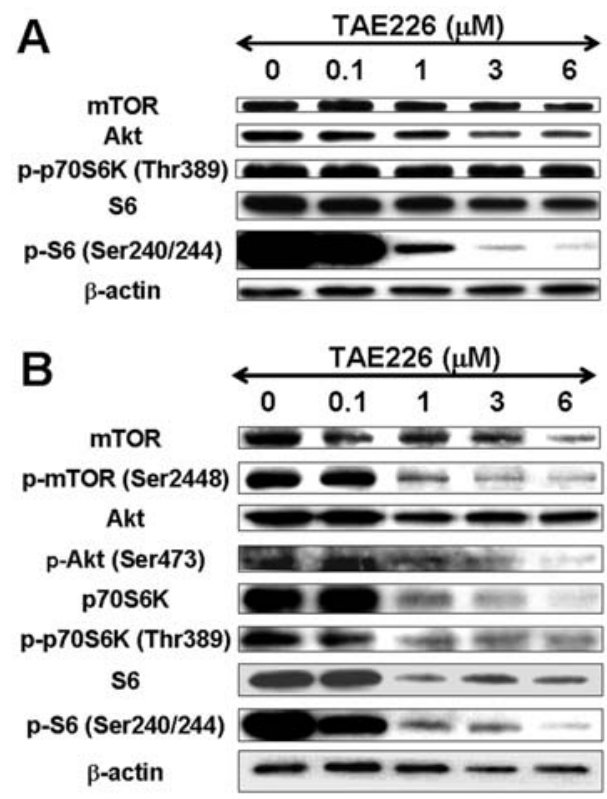

Figure 4. Activations of mTOR and its downstream molecules were inhibited by TAE226 in SEG-1 cells. (A) The expression of mTOR, Akt, and S6 and their phosphorylation status were examined by Western blot at $24 \mathrm{~h} \mathrm{(A)}$ and at $48 \mathrm{~h}$ (B) after the addition of TAE226. B-actin was served as an internal control.

(day 1-8) by a trypan blue exclusion assay to draw growth curve for each condition. SEG-1 cells appeared to be sensitive to TAE226, which is consistent with our previous report, where $\mathrm{IC}_{50}$ of the inhibitor was $0.47 \mu \mathrm{mol} / 1$ in SEG-1 cells (17). The cell proliferation was heavily inhibited and cell density was not increased when the TAE226 concentration exceeded over $0.75 \mu \mathrm{M}$ during a 48 -h treatment (Fig. 1). Microscopic observation revealed that cell morphology was severely damaged in 24 and $48 \mathrm{~h}$ (Fig. 2).

In recent years, preventive and therapeutic strategies for targeting the key molecules involved in the signaling transduction pathways of the cell proliferation, migration, 
and the invasion of tumors have made great progress $(22,23)$. Many specific inhibitors have been discovered and are beginning to be used in clinical trials against cancer. TAE226, as a competitive inhibitor of ATP, can inhibit several tyrosine kinases, in particular FAK and IGF-IR. It was confirmed that TAE226 can suppress glioma proliferation in vitro and in vivo (16). Our result shows that TAE226 can inhibit the proliferation of SEG-1 cells in vitro and that TAE226 offers a therapeutic intervention as a potential strategy for esophageal cancer.

mTOR and S6 were overexpressed in esophageal cancer SEG-1 cells. The expression status of mTOR and its downstream target S6 in SEG-1 cells was detected by RT-PCR and Western blot analysis. The data showed that mTOR and S6 were overexpressed in SEG-1 cells compared to the normal esophageal epithelial cells (KOB-13) (Fig. 3).

mTOR, as a serine/threonine protein kinase, belongs to the phosphatidylinositol kinase-related kinase super family, and is the focus of recent research on signal transduction and cell proliferation. It is believed that mTOR regulates the basic biological process as a control regulator of cell growth (24). Studies on the constitution of the mTOR pathway show that there is a relationship between the disorganization of the mTOR pathway and tumors $(23,25)$. The mTOR signal, together with the PI3K signal, controls the cell proliferation of tumors $(26,27)$. Our result indicates the accordance of the active mTOR signaling and the high growth rate of cancer cells. Since FAK can activate PI3K-Akt pathway to maintain cell growth and survival, inhibition of FAK by TAE226 should modulate activity of mTOR and its downstream signaling. Since we and other groups have shown antiproliferative and proapoptotic effects of TAE226 by inhibiting PI3K-Akt pathway, we newly hypothesized that inhibition of mTOR could also contribute to TAE226-mediated suppression of cell growth.

FAK and IGF-IR inhibition by TAE226 inhibits activation of downstream targets Akt, mTOR, p70S6K and S6. Next we determined activities of Akt, mTOR and their downstream molecules by Western blot analysis in order to explore a possible inhibitory effect of TAE226 on mTOR signaling. Fig. 4 showed that TAE226 inhibited activations of Akt and mTOR as well as those of their downstream molecules such as p70S6K and S6 in $48 \mathrm{~h}$. Interestingly, $1 \mu \mathrm{mol} / \mathrm{l}$ of TAE226 treatment led to a faint reduction of p70S6K phosphorylation and moderate decrease of S6 activity in $24 \mathrm{~h}$ while those phosphorylations were almost completely abolished in $48 \mathrm{~h}$. Suppression of mTOR signaling by inhibition of FAK may need a certain amount of time.

There is a great amount of evidence showing that S6 is a downstream molecule of mTOR. mTOR regulates the phosphorylation of S6 through S6K. The phosphorylated S6 combines with small subunits of ribosome, starting the synthesis of related protein and cell proliferation $(28,29)$. The inhibition of TAE226 on FAK and IGF-IR can affect the phosphorylation of S6 in glioma cells $(15,16)$. We found that the expression and the phosphorylation of Akt, p70S6K and S6 were inhibited when esophageal cancer SEG-1 cells were treated with TAE226. Furthermore, the effect was dosedependent. These data provided the direct evidence that there is a possibility that FAK signaling contacts with mTOR signaling, suggesting the presence of a signal transduction pathway of FAK/PI3K/AKT/mTOR.

Although the function of FAK is not totally clear, it is sure that the inhibition of FAK can affect the phosphorylation of its downstream molecules and is related to cell proliferation and death. We found that when FAK and IGF-IR were inhibited by TAE226, not only phosphorylation, but also the expression of Akt, mTOR and S6 were inhibited. Since FAK is a non-receptor tyrosine kinase, these findings suggest that FAK is involved in the regulation of some gene expression besides its function as a kinase. Research about the mechanism would be a useful future project. Another advantage to use a specific inhibitor targeting a certain molecule which locates upstream of mTOR is that expression and activities of mTOR and related molecules are often upregulated in cancer compared to normal cells/tissues (Fig. 3). Based upon this tendency, TAE226, which was designated to target FAK and has an additional inhibitory effect on IGF-IR, should be a good candidate for a novel therapeutic agent with effective and selective cancer treatment because of its reasonable suppressive effect on mTOR signaling.

In conclusion, our data show the importance of the mTOR signaling pathway on the regulation of cell proliferation and the possible relationship between the FAK signal pathway and the mTOR signaling pathway using the specific inhibitor of FAK. TAE226 can inhibit the activity of mTOR and its downstream molecule S6. TAE226 may be useful for esophageal cancer treatment as a novel therapeutic instrument.

\section{Acknowledgments}

We thank Mr. Tanida for technical assistance.

\section{References}

1. Lambert R and Hainaut P: Esophageal cancer: Cases and causes (Part I). Endoscopy 39: 550-555, 2007.

2. Lambert R and Hainaut P: Esophageal cancer: The precursors (Part II). Endoscopy 39: 659-664, 2007.

3. Wu X, Chen VW, Andrews PA, Ruiz B and Correa P: Incidence of esophageal and gastric cancer among Hispanics, nonHispanic whites and non-Hispanic blacks in the United States: subsite and histology differences. Cancer Causes Control 18: 585-593, 2007.

4. Wu X, Chen VW, Ruiz B, Andrews P, Su LJ and Correa P: Incidence of esophageal and gastric carcinomas among American Asians/Pacific Islanders, whites, and blacks: subsite and histology differences. Cancer 106: 683-692, 2006.

5. Basson MD, Sanders MA, Gomez R, Hatfield J, VanderHeide R, Thamilselvan V, Zhang J and Walsh MF: Focal adhesion kinase protein levels in gut epithelial motility. Am J Physiol Gastrointest Liver Physiol 291: G491-G499, 2006.

6. Sood AK, Coffin JE, Schneider GB, Fletcher MS, DeYoung BR, Gruman LM, Gershenson DM, Schaller MD and Hendrix MJC: Biological significance of focal adhesion kinase in ovarian cancer: role in migration and invasion. Am J Pathol 165: 10871095, 2004.

7. Slack-Davis JK, Martin KH, Tilghman RW, Iwanicki M, Ung EJ, Autry C, Luzzio MJ, Cooper B, Kath JC, Roberts WG and Parsons JT: Cellular characterization of a novel focal adhesion kinase inhibitor. J Biol Chem 282: 14845-14852, 2007.

8. Miyazaki T, Kato H, Nakajima M, Sohda M, Fukai Y, Masuda N, Manda R, Fukuchi M, Tsukada K and Kuwano H: FAK overexperession is correlated with tumour invasiveness and lymph node metastasis in oesophageal squamous cell carcinoma. Br J Cancer 89: 140-145, 2003. 
9. Schaller MD, Hildebrand JD, Shannon JD, Fox JW, Vines RR and Parsons T: Autophosphorylation of the focal adhesion kinase, pp125FAK, directs SH2-dependent binding of pp60 ${ }^{\text {src }}$. Mol Cell Biol 14: 1680-1688, 1994

10. Calalb MB, Polte TR and Hanks SK: Tyrosine phosphorylation of facal adhesion kinase at sites in the catalytic domain regulates kinase activity: a role for Src Family kinase. Mol Cell Biol 15: 954-963, 1995.

11. Parsons JT: Focal adhesion kinase: the first ten years. J Cell Sci 116: 1409-1416, 2003.

12. Larsson O, Girnita A and Girnita L: Role of insulin-like growth factor I receptor signaling in cancer. Br J Cancer 92: 2097-2101, 2005.

13. McCampbell AS, Broaddus RR, Loose DS and Davies PJ: Overexpression of the insulin-like growth factor I receptor and activation of the AKT pathway in hyperplastic endometrium. Clin Cancer Res 12: 6373-6378, 2006.

14. Fottner C, Minnemann T, Kalmbach S and Weber MM: Overexpression of the insulin-like growth factor I receptor in human pheochromocytomas. J Mol Endocrinol 36: 279-287, 2006.

15. Shi Q, Hjelmeland AB, Keir ST, Song L, Wickman S, Jackson D, Ohmori O, Bigner DD, Friedman HS and Rich JN: A novel lowmolecular weight inhibitor of focal adhesion kinase, TAE226, inhibits Glioma growth. Mol Carcinog 46: 488-496, 2007.

16. Liu TJ, LaFortune T, Honda T, Ohmori O, Hatakeyama S, Meyer T, Jackson D, Groot J and Yung WK: Inhibition of both focal adhesion kinase and insulin-like growth factor-I receptor kinase suppresses glioma proliferation in vitro and in vivo. Mol Cancer Ther 6: 1357-1367, 2007.

17. Watanabe N, Takaoka M, Sakurama K, Tomono Y, Hatakeyama S, Ohmori O, Motoki T, Shirakawa Y, Yamatsuji T, Haisa M, Matsuoka J, Beer DG, Tanaka N and Naomoto Y: Dual-tyrosine kinase inhibitor for focal adhesion kinase and insulin-like growth factor-I receptor exhibits anticancer effect in esophageal adenocarcinoma in vitro and in vivo. Clin Cancer Res 14: 4631-4639, 2008.
18. Xia H, Nho RS, Kahm J, Kleidon J and Henke CA: Focal adhesion kinase is upstream of phosphatidylinositol 3-kinase/ Akt in regulation fibroblast survival in response to contraction of type I collagen matrices via a $\beta 1$ integrin viability signaling pathway. J Biol Chem 279: 33024-33034, 2004.

19. Reif, S, Lang A, Lindquist JN, Yata Yutaka, Gabele E, Scanga A, Brenner DA and Rippe RA: The role of focal adhesion kinase-phosphatidylinositol 3-kinase-Akt Sugnaling in hepatic stellate cell proliferation and type I collagen expression. J Biol Chem 278: 8083-8090, 2003.

20. Tang CH, Yang RS, Huang TH, Lu DY, Chang WJ, Huang TF and $\mathrm{Fu} \mathrm{WM}$ : Ultrasound stimulates cyclo-oxygenase-2 expression and increases bone formation through integrin, focal adhesion kinase, phosphatidylinositol 3-kinase, and Akt pathway in osteoblasts. Mol Pharmacol 69: 2047-2057, 2006.

21. Akagi T, Murata K, Shishido T and Hanafusa H: v-Crk activates the phosphoinositide 3-kinase/AKT pathway by utilizing focal adhesion kinase and H-Ras. Mol Cell Biol 22: 7015-7023, 2002.

22. Sarkar FH and Li Y: Targeting multiple signal pathways by chemopreventive agents for cancer prevention and therapy. Acta Pharmacol Sin 28: 1305-1315, 2007.

23. Wan X and Helman LJ: The biology behind mTOR inhibition in sarcoma. Oncologist 12: 1007-1018, 2007.

24. Schmelzle T and Hall MN: TOR, a central controller of cell growth. Cell 103: 253-262, 2000

25. Hidalgo $\mathrm{M}$ and Rowinsky EK: The rapamycin-sensitive signal transduction pathway as a target for cancer therapy. Oncogene 19: 6680-6686, 2000

26. Wullschleger S, Loewith $\mathrm{R}$ and Hall MN: TOR signaling in growth and metabolism. Cell 124: 471-484, 2006.

27. Shaw RJ and Cantley LC: Ras, PI3K and mTOR signaling controls tumour cell growth. Nature 441: 424-430, 2006.

28. Hay N and Sonenberg N. Upstream and downstream of mTOR. Genes Dev 18: 1926-1945, 2004.

29. Inoki K, Ouyang H, Li Y and Guan KL: Signaling by target of rapamycin proteins in cell growth control. Microbiol Mol Biol Rev 69: 79-100, 2005. 